\title{
LOS VIEJOS FANTASMAS VUELVEN AL PRESENTE: LO GÓTICO EN LA LITERATURA ESPAÑOLA ACTUAL ${ }^{1}$
}

\author{
MIRIAM LÓPEZ SANTOS² \\ Universidad de León
}

Como un ir y venir, como en un eterno retorno, la literatura recupera figuras, elementos, mitos que traspasan las fronteras que los vieron florecer, que trascienden al tiempo, como en una lucha contra la dictadura del mismo, y acaban por alcanzar la categoría de tópicos, asentarse en nuestras conciencias y anclarse en el ideario colectivo. Un de los muchos movimientos capaces de regalar a la literatura una formidable cosecha, una extraordinaria colección de mitos que no han perdido vigencia con el transcurso de los siglos fue el de la novela gótica ${ }^{3}$.

\footnotetext{
${ }^{1}$ El presente trabajo se centrará en analizar una colección de relatos de reciente publicación Drácula y Frankenstein rastreando los elementos del goticismo primitivo que aún perviven en ellos. De este modo podremos encontrar las claves que vendrán a determinar alguno de los vínculos o "el diálogo" que se establece entre el pasado y el presente perpetuando de este modo dicha tradición literaria de lo gótico. 2 Personal Investigador en Formación. Universidad de León. Correo-e: mlops@unileon.es Recibido: 0312-2008; segunda versión: 15-03-2009.

${ }^{3}$ Es cierto que la novela gótica tomó estos mitos de las fuentes orales más primitivas formando parte, por ello, de la herencia permanente de la humanidad, como sostuviera Lovecraft (1989: 15), para quien el fantasma que se aparece y exige que sean enterrados sus huesos, el amante que regresa del más allá para llevarse con él a su esposa viva, el demonio de la muerte o el hombre lobo no son sino herederos de toda una rica tradición medieval. Sin embargo, también es cierto que bajo la pluma de los narradores góticos adquirieron renovadas propiedades y sufrieron un impulso que los caracterizó definitivamente, tal y como los entendemos en nuestros días.
} 
La novela gótica surgió a la sombra de la Inglaterra del Siglo de las Luces, de su neoclasicismo ilustrado, de su desproporcionado culto a la razón ${ }^{4}$, cuando el rechazo a lo sobrenatural, en la vida cotidiana, llevó aparejado, en su propio nacimiento, una férrea condena de su uso literario y estético. Como movimiento transgresor que fue, la novela gótica, que transitaba por los laberintos más inhóspitos e insospechados de la conciencia humana, había conocido en ese país, y por extensión en una gran parte de Europa, un período realmente dorado. Venerada, en principio, por un público que devoraba sus producciones, acusó desde muy temprano, sin embargo, el desprestigio de la crítica, que cuestionaba su valor literario y que reprochaba sus carencias así como su excesiva dependencia de la fórmula. Quedó confinada, por ello, a unas circunstancias espacio temporales concretas que vinieron a minarla en su prestigio, a condicionar su desarrollo y a prefigurar al mismo tiempo su trascendencia posterior ${ }^{5}$. El género se agotó; su hálito vital duró apenas tres décadas, pero no agonizó del todo; en sus entrañas, como cantos de nuevo ave fénix, se forjaron subgéneros inéditos que aún hoy en día siguen gozando

\footnotetext{
${ }^{4}$ Podemos afirmar que la novela gótica nació por un cúmulo de circunstancias, contradictorias en ocasiones, aunque curiosamente unidas de manera indisoluble: sociales, políticas, históricas y evidentemente literarias. Este poligenismo causal determinó su nacimiento, pero también su configuración, como fruto indiscutible de un espacio, Inglaterra, y de un período, El Siglo de las Luces. Pues, como ya apuntara Coleridge (General Character of the Gothic Literature and Art (1818), en Thomas Middleton Rayson (ed.), Coleridge's Miscellaneous Criticism, Cambridge, Harvard University Press, 1936, pp. 196.,) este movimiento literario fue "inglés en su origen, inglés en sus materiales e inglés por readopción".

${ }^{5}$ Chandler se hace eco en "el simple arte de matar", como señala Noumbissi (2001:102), de los límites difusos que presentan estos géneros y de las trabas a las que han tenido que enfrentarse para superar su condición de paraliteratura; por ello señala que no existen "formas vitales e importantes del arte" sino que solo existe el arte, para continuar afirmando que estos géneros son dificultosos, aunque cualquier género literario debe lidiar con problemas inherentes al mismo. La novela policiaca habría heredado, del mismo modo, de la novela gótica la problemática y la marginación más allá de las estructuras narrativas.
} 
de plena actualidad y que le superarían en público, en vigor y en calidad literaria: el relato policiaco ${ }^{6}$ o la literatura fantástica ${ }^{7}$.

Podemos afirmar que llegaría más lejos aún, pues de su imperante rechazo al mundo circundante prendió la chispa que avivaría la llama del que según la crítica ha sido el movimiento artístico más exacerbado e hiperbólico: el Romanticismo. Y si la novela gótica fue, en efecto, y como confirman Victor Sage y Richard DavenportHines, la punta de lanza literaria de la incipiente sensibilidad romántica, Frankenstein y Drácula, hijos y herederos de aquella oscuridad, pero emblemas de la nueva búsqueda de libertades y del deseo de inmortalidad al mismo tiempo, se configuraron como mitos imperecederos, siempre susceptibles, por su enorme versatilidad, de generar nuevas lecturas en lugar de agotarse. Pues estos mitos, que no son sino la codificación de los temores producidos por la Ilustración trasformados

\footnotetext{
${ }^{6} \mathrm{El}$ investigador Fereydonum Hoveyda fue el primero en sostener, desde el inicio de sus estudios, que la novela policíaca, como relato construido a partir de acontecimientos fantásticos, tiene un claro precedente en la novela gótica. (Historia de la novela policíaca, Madrid, Alianza Editorial).

Trabajos más actuales como el que corresponde al profesor Daniel F. Ferreras, "La poética del desorden: hacia una definición semi-crítica de un género fantástico" de 2003, continúan la línea marcada por Fereydonum Hoveyda y apuntan más lejos al afirmar que no solo la novela gótica sino todo el género conocido como "fantástico puro" podría explicarse y entenderse en términos de la novela policíaca.

De hecho, los textos fundadores de la novela policíaca (Balzac, Gaboriau y Poe) fueron redactados por escritores de formación "gótica" y en una perspectiva híbrida, como Los crímenes de la calle Morgue de Poe, obra catalogable en los dos géneros (de hecho, las adaptaciones cinematográficas encaran este texto fundador según una estética claramente terrorífica), como bien ha demostrado Varma en el epílogo a The Gothic Flame (1956).

7 Desde el comienzo de los estudios sistemáticos del género fantástico con el formalista Tzevetan Todorov (1973), se ha venido sosteniendo que el inicio de la literatura fantástica, entendida esta como la dependencia directa de "la idea de realidad que tiene el lector" (Roas, 2004: 47), se encuentra indudablemente en la novela gótica (y en El castillo de Otranto, 1763), por pertenecer esta a un período en el que la razón había prescindido en la vida cotidiana de prodigios, supersticiones o seres extraordinarios, lo que abriría el paso a su empleo en la literatura desde una nueva perspectiva de transgresión.
} 
en monstruos, consiguen hablarnos de conflictos contemporáneos al mostrar lo peor y lo mejor de nuestro tiempo ${ }^{8}$. Y he aquí el secreto de su éxito y supervivencia a lo largo de los siglos, la capacidad de transformación y adaptación al presente, no sólo en las lecturas, sino a través de continuas reelaboraciones.

La recién publicada colección de relatos Frankenstein y Drácula, revisa estos mitos bajo la mirada de algunos de los escritores españoles más en boga, que los dotan de nuevas particularidades y les confieren desconocidos valores, fundamentalmente porque, al contrario que en las novela de Bram Stoker y de Mary Shelley, los monstruos toman aquí la palabra para relatar todas sus ansias y sus insatisfacciones ${ }^{9}$. Y así descubrimos a un Drácula_escondido en la sombra (Menéndez Salmón) que "acumula el cansancio infinito de su condena" (Lago, 2008: 141), rechaza su inmortalidad (Carmen Posadas) y, asqueado del mundo, busca incansable, de la mano de José María Merino, un digno relevo; o a un renovado Frankenstein que no duda en considerarse a sí mismo en "Segunda resurrección" de Lola Beccaria "un superhombre, adelantado a mi tiempo, incomprendido por mis cobardes semejantes, tan faltos de horizontes como mediocres y mezquinos" (Beccaria, 2008: 73).

Una pregunta surge, sin embargo, en estos momentos: ¿qué sería de estos mitos en los albores del siglo XXI si no los envolviera el conjunto de elementos que

\footnotetext{
${ }^{8}$ Los monstruos que nos encontramos en las páginas de estos relatos responden, del mismo modo, a una tendencia en alza, en los últimos años, en el marco de la literatura fantástica: la presentación de monstruos y seres excepcionales y señala David Roas (2008: 51) los siguientes: "("Mi hermana Elba", 1980, de Cristina Fernández Cubas; “El increíble hombre inapetente”, 1982, de José Ferrer-Bermejo; “El cliptodermo" y “Mi mamá me mima", 1988, de Laura Freixas)".

9 Aquí los monstruos representan al ser humano corriente y como expone David Roas nos encontramos con un "retrato del individuo contemporáneo como un ser perdido, aislado, desarraigada, incapaz de adaptarse al mundo, tan descentrado como la realidad que le ha tocado vivir [...] Son seres que buscan una identidad que no se puede alcanzar, pues se hace evidente que esta es siempre cambiante, provisional. Personajes que, perdidos en ese mar de signos indescifrables que es la realidad, tratan infructuosamente de acomodarla a sus ideas y deseos [...]" (Roas, 2008: 49).
} 
les dieron la vida? o dicho de otro modo, ¿qué conservan estos seres infestos que aún recorren nuestras conciencias y nuestras pesadillas diarias y que son la representación palmaria de las angustias que envuelven al nuevo hombre de un ideario gótico primigenio? En efecto, no solo en la aparición de los mitos reconocemos el legado de la novela gótica; los narradores apoyan su composición en el respeto a una lógica narrativa, entendiendo por esta el conjunto de elementos recurrentes que configuran su estructura y que delimitan sus fronteras con respecto a movimientos cercanos; suspense, terror y tendencia al exceso subsisten en estos relatos remitiendo a un más que palpable sustrato gótico.

La percepción de esta literatura gótica implicaba una manera de leer y estructurar el relato atenta a una consideración compleja y global de la realidad, algo mucho más misterioso, inquietante y perturbador de lo que pudiera parecer a simple vista. (Barella 1994: 11). Parte, como apuntara David Roas (2001: 17), de una obligada ruptura del orden establecido, de una trasgresión de nuestra realidad cotidiana ${ }^{10}$. Los personajes de aquellas novelas se encontraban, a su paso, con una serie de seres o situaciones extrañas e inexplicables que transgredían y ponían en jaque aquella realidad objetiva. En torno al elemento que provoca la transgresión se organizan cada uno de los relatos que ahora analizaremos; así, el monstruo del bosque que persigue a la niña en "El lago", de Espido Freire o la presencia inmutable y asediante del Maestro en "Vampiros en Weimar", de Ricardo Menéndez Salmón, se revelan como elementos que no solo amenazan la disposición de nuestro mundo sino que provocan, del mismo modo, una profunda sensación de angustia y horror en los personajes y por extensión en el lector.

\footnotetext{
${ }^{10}$ La novela gótica, como subgénero impulsor y a la vez dependiente del género fantástico necesita de la obligada ruptura del orden establecido. Este aspecto ha sido estudiado en profundidad en nuestros días por David Roas $(2001,2004,2006)$ quien sostiene que la irrupción de lo sobrenatural en el mundo real y, sobre todo, la imposibilidad de explicarlo de forma razonable es el único rasgo definitorio del género fantástico y añade "La transgresión que define a lo fantástico solo se puede producir en relatos ambientados en nuestro mundo, relatos en los que los narradores se esfuerzan por crear un espacio semejante al del lector" (Roas, 2001:17-18).
} 
En efecto, en el marco de la novela gótica, estos seres son, ante todo y más allá de su innegable responsabilidad en la transgresión, auténticos objetos de terror y como tales son utilizados por los escritores, para conseguir el anhelado efecto de lo sublime ${ }^{11}$. De hecho, el miedo alcanza de la mano de los góticos el estatus de elemento estético; se convierte, como señalara Molina Foix (2003: 25), en "algo más que un tema o una actitud, puesto que influye en la forma, el estilo y las relaciones sociales del texto". El empleo del miedo como mecanismo constitutivo y estructurador se aprecia con claridad en los nuevos relatos $\mathrm{y}$, de esta manera, asistimos atentos a la "inquietud" que sobrevuela el texto y al personaje principal de "La mansión del páramo" de Lourdes Ventura, a quien la curiosidad puede más que el miedo en el momento de adentrarse junto con el lector en los subterráneos malditos de la casa.

La mañana se fue oscureciendo poco a poco y a eso del mediodía una niebla espesa cayó sobre el páramo. Me sentí afiebrada y alcanzaba a percibir más ruidos de lo normal procedentes de la galería que comunicaba con el sótano. Estaba aterrada, por eso no se de dónde saqué fuerzas para llegar hasta la lavandería y rebuscar en el armario la llave de las termas (Ventura, 2008: 179).

${ }^{11}$ Fue precisamente el filósofo Edmund Burke (2005: 86-87) el primero que, percatándose de este hecho, supo ver los efectos del miedo y su contribución a lo sublime cuando afirmó: "No hay pasión que robe tan determinantemente a la mente todo su poder de actuar y razonar como el miedo. Pues el miedo, al ser una percepción del dolor o de la muerte, actúa de un modo que parece verdadero dolor. Por consiguiente, todo lo que es terrible en lo que respecta a la vista, también es sublime [...]; es imposible mirar algo que pueda ser peligroso, como insignificante o despreciable [...]. Es el terror la fuente de todo lo sublime". El miedo se alza, según este filósofo, como condición indispensable para poder provocar el sentimiento de lo sublime, puesto que recordamos el dolor y la amenaza de muerte más vivamente que el placer (Lovecraft, 1989: 9); dicho de otra manera, el miedo no suscitará la intención deseada en el lector si este no dispone de un verdadero sentimiento de lo sublime. Y, por supuesto, cuanto más completa y unificadamente consiga un relato sugerir dicha sensación, más perfecto será como obra de arte de este género (Lovecraft, 1989: 12).

Ann Radcliffe (Clery, 2000: 168), madre del género gótico, en la misma línea de Burke, supo también desde el principio que la clave de toda novela gótica estaba en la consecución de este efecto. Debía ser el terror, según la propia escritora, el motivo que caracterizase a este tipo de literatura, evitando, por completo, cualquier síntoma de repugnancia que más que miedo infundara horror. 
De la misma manera, en "El relevo" de Merino, nos sentimos partícipes del terror que sufre el personaje que se debate entre el pánico que le provoca el contacto con estos seres por su papel de cazavampiros y la extraña fascinación que sufre ante su presencia y así se lo refiere el mismo Drácula:

[...] al llegar percibiste inmediatamente la sensación, aquella emanación putrefacta que tan embriagadora y hasta sabrosa te resultó en la niñez, cuando llegaste a restregar tu cuerpo con el de aquella oveja muerta [...] Y es ahora, por fin. Has comprendido quién eres, quién soy, la trampa que al fin ha hecho que nos encontremos (Merino, 2008: 38-42).

La transgresión provoca, asimismo, una serie de preguntas y saca a la luz una sucesión de enigmas o misterios a los que el protagonista del relato gótico está obligado a enfrentarse. Estos misterios se muestran cargados de una enorme complejidad, como explicara Macherey (1978: 40-46), pues cada objeto, cada situación, cada hecho, cada personaje incluso, parecen esconder algo: un pasado oculto, un secreto disperso y fragmentario que guarda relación con los acontecimientos y que supone una búsqueda hermenéutica que constituye el verdadero proceso de la narración (Ramos Gómez 1988: 34). Desde el comienzo de estos relatos sabemos que hay algo misterioso, ininteligible, terrorífico, detrás del elemento trasgresor, algo que se manifiesta fundamental, pero que, sin embargo, se nos presenta como desconocido12. Así, la protagonista de "La mansión del páramo" de Lourdes Ventura deberá descubrir, paso a paso y a su medido tiempo, el secreto que se esconde tras la supuesta maldición de la familia, las sucesivas prohibiciones y los extraños ruidos que provienen de los subterráneos ${ }^{13}$.

\footnotetext{
12 Se trata de un mundo lleno de trampas, vacíos, incertidumbres y espejismos que Rosalba Campra justificó gracias a lo que ella había denominado, "el paradigma del silencio"12; el silencio de personajes y narrador ante los hechos planteados y los vacíos en la casualidad de los acontecimientos vendrían a justificar las fracturas e interferencias que dificultan el acceso al saber que el lector busca. Vacíos estos que solo podrían ser cubiertos e interpretados, según este autor, acudiendo a "la autonomía de las leyes de la ficción y cierta regularización cultural del texto".

${ }^{13}$ Las maldiciones que sobrevolaban el relato de los acontecimientos y que sacudían a sus personajes pueden considerarse motivos recurrentes por estar presentes en los mismos fundadores del género
} 
Y puesto que la lógica narrativa del modo gótico consiste, sobre todo, en retrasar la revelación última que pondrá fin a la aventura del protagonista y al texto, el relato durará entonces lo que dure el misterio; cuando la realidad o la explicación se imponen, el relato llega, inexorable, a su fin. Esta técnica del suspense es empleada con frecuencia por los nuevos narradores. En "Carta dirigida a las novias de Drácula" de Carmen Posadas, el conde, sin abandonar su papel, se pone en la piel de un detective; trata de recuperar los enigmas que rodean a los terribles asesinatos que se han venido cometiendo en Londres a finales del siglo XIX ${ }^{14}$. La intención sin embargo, y he aquí la novedad del texto, ya no es solamente delatar sino el hecho de encontrar un ser que se sitúe a la altura de su condición: "el enorme privilegio de la vida eterna", "un colega del mal, un transgresor" (Posadas 2008: 64) y acaba por descubrir la identidad del asesino más famoso de todos los tiempos (Jack el Destripador). La personalidad cambiante de los personajes como recurso gótico, esconde una inversión de valores que complica el entramado del relato; el que trata de resolver el misterio es un ser maligno y el asesino es, aparentemente, un respetable escritor de cuentos infantiles (Lewis Carroll), pero el esquema sigue siendo el mismo: la búsqueda de un enigma en medio de un ambiente hostil en el que nada es lo que parece ser.

A crear esta ambigüedad y confusión contribuye, del mismo modo, la frecuente narración en primera persona y a veces en forma epistolar, presente en todos y cada uno de los relatos. Según señalara Todorov (1982: 101-103), la utilización de la primera persona es la única característica fundamental que debiera respetar este tipo de relatos. Al identificarse ambas funciones (narrador $\mathrm{y}$ gótico. Horace Walpole inicia su Castillo de Otranto con la maldición que asedia a su señor y que tiene que ver con el verdadero heredero del propio castillo.

${ }^{14}$ Idéntico esquema encontramos en "La mirada del deseo" de Paula Izquierdo. El relato se estructura en torno al juego detectivesco que se establece entre el doctor Frankenstein y el monstruo: "[...] el monstruo dejó en distintas ocasiones a lo largo de mi persecución, como ya he dicho, rastros para que yo pudiera seguirlo en un juego macabro y sin fin. A veces, perdía sus huellas y él se encargaba de que las retomara. Su forma de estimular mi olfato, mi intuición y mis fuerzas para continuar las pesquisas para darle caza fue más cruel de lo que uno pueda imaginar" (Izquierdo, 2008: 52). 
protagonista), en “El príncipe de las tinieblas” de Martín Garzo, por ejemplo, encontramos, por un lado, que la historia resulta creíble para el lector, que no desconfía de la veracidad de los acontecimientos contados por quien los ha vivido (basándose en la precisión de fechas y lugares con que ilustra la historia: Valladolid a mediados del siglo XX); pero, al mismo tiempo, somos conscientes del engaño al que nos somete este, pues, aún conociendo de antemano el devenir de la historia, su papel de narrador "tramposo" le insta a retrasar al máximo el esperado desenlace final.

Del mismo modo, la complejidad narrativa aparece apoyada también en una serie de relatos o historias paralelas que se superponen provocando cierta sensación de caos. Estas nuevas narraciones, y a pesar de su brevedad, heredan de las novelas góticas la estructura de caja china que remite directamente a la esencia misma de la novela gótica: la búsqueda del exceso. Raúl Guerra Garrido en “Te prohíbo contarlo" emplea esta técnica al alternar historias de diferente índole, distantes en el tiempo y en el espacio y que no parecen mantener relación alguna con la trama inicial. Se trata, en realidad, de un intento por mantener y aumentar la tensión del discurso narrativo.

Esa tendencia al exceso, muy del gusto de los narradores góticos, entronca asimismo con la repetición casi obsesiva de horrores y situaciones repugnantes, así como con una compleja y reiterada escenografía de elementos terroríficos. Estos escritores tendían, por una parte, a adornar sus relatos con todos los horrores del pecado, de la putrefacción y de la corrupción física, en su pretensión de enfrentar al lector con todo aquello que abominaba y le repugnaba15; la intención no era otra sino

\footnotetext{
${ }^{15}$ Las novelas góticas solían enfrentar al lector a temas prohibidos o temas tabú, logrando que este se identificara con el dolor padecido por los protagonistas. Se trataba normalmente de contenidos condenados y censurados que, frente a lo esperable, no solían aparecer, por lo general, expuestos de manera evidente (porque al fin y al cabo "todo lo que tiene que ver con el deseo debe permanecer siempre en la sombra. Lo que no puede nombrarse, eso es el deseo" (Martín Garzo, 2008: 83), sino que, en la mayoría de las ocasiones, son tan solo insinuados por sus autores. Uno de estos denominados temas tabú que se recrea en el exceso era el sexo, que encontramos planteado como motivo recurrente, del mismo modo, en "la mirada del deseo": "Aquella vez fue ella la que se despojó de la ropa poco a
} 
conseguir neutralizar su desagrado mediante la siempre perseguida fascinación. Lo vemos claramente en "La mirada del deseo", de Paula Izquierdo, narración en la que el capitán de un barco, refiere al destinatario, en la que cree ser su última noche, las desgracias que por culpa del monstruo sufrió a la largo de su vida el Doctor Frankenstein. El relato de sus incesantes persecuciones alterna con el terror y las continuas, y hasta desproporcionadas podríamos decir, imágenes explícitas que sacan a la luz la repugnancia que él mismo siente ante la presencia de este ser maligno. La descripción física que de Renfiel encontramos en "Vampiros en Weimar" muestra, del mismo modo, esta búsqueda del exceso: "un ser viscoso, sucio, putrefacto [...] un fétido hijo del vampiro. Un torturado. Un esclavo. Un hechizado" (Menéndez Salmón, 2008: 15).

Será el ambiente gótico, sin embargo, esa escenografía espeluznante, sublime y ya tópica ${ }^{16}$ a la que con más frecuencia se acuda en estos relatos para crear ese efecto

poco, deteniéndose en cada prenda. Debajo del vestido de seda, floreado $t$ ajustado en la cintura, llevaba una especie de vestidito negro con trasparencias. Él la miraba extasiado desde el lecho, viendo cómo ella arqueaba la espalda, tocándose los pechos, gustándose, dándose los caprichos que luego compartiría con él" (Izquierdo, 2008: 59).

16 Sería de nuevo Edmund Burke el encargado de determinar y fijar, desde el punto de vista estético, las propiedades del espacio gótico, estableciendo una distancia más que considerable con la tradición anterior. Habla de un espacio determinado por la intersección de una serie de elementos imprescindibles, sin los cuales, no se podría caracterizar cierto texto como perteneciente a este género; inmensidad, infinidad, oscuridad, soledad o brusquedad como elementos constitutivos de lo sublime, determinan el espacio de estas novelas convirtiéndolo, más que en espacio referencial, en lo que podríamos denominar espacio estético. Los narradores góticos no solo pretenden facilitar al lector la labor de percepción de los acontecimientos de la historia, sino que también intentan hacerles partícipes de la magnificencia y sublimidad del mismo. Kant, también en esta misma línea, lo calificó de espacio terrorífico, repleto de lóbregas encinas, alamedas sombrías y secretas, tétricas sombras, luces tenebrosas, y todo envuelto en una oscuridad espeluznante, fría, casi apocalíptica. Una escenografía, antesala de lo que años más tarde sería el paisaje romántico, extrema, cercana a la teatralidad, la misma boca del infierno. Este espacio sublime lo encontramos descrito en el relato Gustavo Martín Garzo "El príncipe de las tinieblas" y en el de Lourdes Ventura "La mansión del páramo": 
deseado. Pero, ¿qué podríamos decir de aquel escenario de terror, de aquel telón de pesadilla, de aquel artificio terrible y asfixiante que heredó el Romanticismo y sin el que la novela gótica perdería sus significaciones primeras?, ¿Qué puede quedar de todo aquello traspasado el umbral del siglo XXI? Narradores como Ángeles Caso, con "La vida era amor", optan por sacrificar la necesaria verosimilitud del escenario reconocible por el lector, en favor de la fidelidad al modelo clásico, en el que imperan los escenarios remotos y los paisajes sublimes a la manera de Radcliffe. La escenografía gótica del exceso se manifiesta en la sala principal de Villa Diodati, donde Mary Shelley, protagonista del relato, engendró el Frankenstein "la noche en que (en la pretensión de jugar impunemente con lo innombrable) los monstruos cobraron vida" (Caso, 2008: 12):

Ah , sí, aquella habitación, la sala de Villa Diodati donde todo empezó, las tapicerías doradas y verdes, la gran mesa de mármol, el reloj pompeyano sobre la consola, y aquellas figuras a ambos lados de la chimenea, dos pequeños mascarones de mármol que representaban dos sátiros pero que, iluminados por las llamas, parecían dos horribles demonios vivos (Caso, 2008: 11)

No obstante, un espacio ancestral, perdido entre los pliegues del tiempo, carece de cualquier verosimilitud en la era del cientificismo en la que nos encontramos inmersos. Los nuevos narradores son conscientes de la necesidad de un espacio verosímil, más si tenemos en cuenta que la verosimilitud resulta imprescindible, como apunta David Roas (2004: 47), para alcanzar una impresión correcta sobre el lector, esa ilusión de lo real que Barthes denominara efecto de la realidad. De esta manera, los relatos se emplazan en lugares perfectamente reconocibles, marcados por el culto a la cotidianidad pero que esconden, del mismo modo, las obsesiones e inquietudes con las que un lector actual podría sentirse

\footnotetext{
“la niebla baja envolvía la noche. Los árboles del paseo del príncipe, en la oscuridad, tenían algo de cerrado, de hermético. Me pareció que todos estábamos prisioneros dentro de una gran jaula de la que no podíamos escapar" (Martín Garzo, 2008: 94).

“Aquila niebla espesa y persistente era portadora de malos presagios [...] la negrura de las colinas calcinadas que se alzaban en semicírculo" (Ventura, 2008: 165).
} 
identificado. El castillo como recinto cerrado, casi herméticamente ${ }^{17}$, dará paso a sanatorios, hospicios o mansiones, como nuevos espacios de la opresión, aislados geográficamente y marginados del conjunto de la sociedad, pero que se descubren como renovados escenarios de pesadilla. El hospicio de Londres, el Sanatorio Argos donde permanece Renfiel o un caserón apartado en el condado de Yorkshine simbolizan el confinamiento y aparecen como prisión, como coacción de la libertad del protagonista, lo que termina por configurarlo como una expresión metafórica de este y de sus obsesiones. Así describe la protagonista “La mansión del páramo":

A lo lejos divisé un caserón inmenso con almenas que sobresalían en la fachada, y ventanas alargadas, como de iglesia [...] Me sobrecogió el silencio de aquel lugar, el jardín invadido por la maleza salvaje y el aspecto gris y amenazante de la fachada. [...] los muros parecían estremecerse (Ventura, 2008: 168-169).

Podemos apreciar entonces cómo el espacio gótico se transforma de acuerdo con el nuevo siglo, pero respeta las reglas clásicas, es más, se mantiene fiel a las mismas, pues de Transilvania a Londres, y del pasado al presente, los lugares por los que estos monstruos y los personajes que sufren sus efectos transitan no hacen sino señalar buena parte de los lugares donde se alojan nuestros propios miedos (Lucendo, 2008).

\footnotetext{
${ }^{17}$ La obsesión de esta literatura por el espacio cerrado del castillo se sitúa en estrecha relación con la obsesión por el pasado que comenzó a proliferar en las últimas décadas del siglo XVIII. El castillo se caracterizaba por estar casi siempre en ruinas y en medio de un paisaje desolado y yermo, no domesticado y, por lo tanto, sublimemente incomprensible. Más que un decorado, no obstante, "era la evidencia de que no hay construcción que no lleve en sí misma el germen de la propia destrucción" (Molina Foix, 2003: 13). Se privilegiaba el castillo como exponente de determinados valores dado que pretendía simbolizar la opulencia, la hegemonía y la superioridad de un poder feudal venido a menos, así como la opresión con que se sujetaba al súbdito, especialmente a la mujer y a los considerados inferiores. Un entorno cerrado como epítome del aislamiento feudal y símbolo de la diferencia histórica entre el pasado imaginario y el presente de la narración, que se convertiría en marco idóneo para situar las tétricas y siniestras tramas góticas, pues, no olvidemos, que los castillos, y sobre todo los castillos en ruinas, solían, o al menos esto afirmaban multitud de comentarios supersticiosos, estar frecuentados por fantasmas.
} 
En suma, estos nuevos relatos están marcados, más allá de los monstruos que recuperan, por el misterio, la ambigüedad y la tendencia al exceso en la acción, en el lenguaje y en la arquitectura. Si a esta fascinación por crear tensión se le añade una sensación de temor y maldad, surge un compuesto de emoción intensa y provocación imaginativa que remite indudablemente al modo gótico por suponer la auténtica clave de este. En este sentido, si no ya la novela gótica, muchos de los elementos que la configuraron sobrevivieron, al margen del canon, la mayoría de las ocasiones, al paso de los siglos y aún hoy gozan, como queda constatado, de cierta actualidad. Entonces podríamos finalizar preguntándonos, ¿cómo explicar su escasa difusión en la literatura canónica?, ¿es que el mundo editorial no es en absoluto propicio a las extravagancias, lo diferente, o es que los escritores seducidos por el lado más oscuro de lo fantástico no se atreven a serlo plenamente? No podemos aventurar a través de estos relatos una nueva literatura, pero sí se puede advertir una tendencia creciente que, más allá de novelas y cuentos juveniles, recupera este subgénero que movió masas, azuzó espíritus y levantó conciencias en tiempos pasados. Las últimas novelas de Pilar Pedraza, Eduardo Mendoza, Cistina Fernández Cubas, la propia Irene Gracia y más recientemente Carlos Ruiz Zafón ${ }^{18}$, entre otros, son una muestra de que el hombre, a pesar de todo y de todos, se siente atraído intemporalmente por ese mundo subversivo, por esa voz que nos llama continuamente desde la oscuridad.

\section{BIBLIOGRAFÍA}

AA.DD. (2008): Drácula, Madrid: 451 editores.

AA.DD. (2008): Frankenstein, Madrid: 451 editores.

BARELLA, J. (1994): “La literatura fantástica en España”, Anthropos, n 154-155 (Marzo-abril 1994), pp 11-20.

\footnotetext{
18 Títulos como "Las novias inmóviles", "La fase del rubí", "Las joyas de la serpiente", "La pequeña Pasión" de Pilar Pedraza, La verdad sobre el caso Savolta, El misterio de la cripta embrujada, El laberinto de las aceitunas de Eduardo Mendoza; El coleccionista de almas perdidas de Irene Gracia; Parientes pobres del diablo de Cristina Fernández Cubas o Marina y El príncipe de la niebla de Carlos Ruiz Zafón.
} 
CAMPRA, R. (1991): “Los silencios del texto en la literatura fantástica”, El relato fantástico en España e Hispanoamérica, Madrid: Sociedad Estatal Quinto Centenario.

CLERY, E. J. y Miles, R. 2000. Gothic documents. A sourcebook. 1700-1820. Manchester University Press. Manchester and New York.

FERRERAS, F. D. (2003): “La poética del desorden: hacia la definición semio-crítica de un género fantástico", Actas de las $2^{a}$ Jornadas sobre literatura fantástica, Madrid: Secretaría de Estado de Cultura, Secretaría General Técnica. Pp. 11-23. HOVEYDA, F. Historia de la novela policíaca, Madrid, Alianza Editorial.

LOVECRAFT, H. Ph. (1984): El horror en la literatura, Madrid: Alianza.

LUCENDO, S. (2008): “Lo monstruoso no caduca”, http://revistaliterariaazularte. blogspot.com/2008/06/santiago-lucendo-lo-monstruoso-no.html (consultado 15 de octubre de 2008).

MOLINA FOIX. 2003. “Ensayo introductorio a El Monje”, Madrid, Cátedra

NOUMBISSI, N. (2001): "Poe no inventa el cuento y el delito; al detective tampoco", Acta literaria, no.26, p. 99-115.

RAMOS GOMEZ, M. T. (1988): Ficción y fascinación: literatura fantástica prerromántica francesa, Valladolid, Universidad, Secretariado de publicaciones, D. L.

ROAS, D. (2001): "La amenaza de lo fantástico", Teorías de lo fantástico, Madrid, Arco libros. pp. 7-44.

"Lo fantástico: literatura y subversión" (dossier monográfico), Quimera, 218-219 (Julio-agosto de 2002), pp.35-40.

ROAS, D. y CASAS, A. (2008): "Prólogo" a su ed. de La realidad oculta. Cuentos fantásticos españoles del siglo XX. Palencia: Menoscuarto ediciones.

TODOROV, T. (1982): Introducción a la literatura fantástica, Barcelona, Ediciones Buenos Aires. 